\title{
LARGE NONFUNCTIONAL ADRENO CORTICAL CARCINOMA MASQUERADING AS RENAL CELL CARCINOMA: A CASE REPORT WITH REVIEW OF LITERATURES
}

\author{
Ahsan Ahmad ${ }^{1}$, Kaushal Kunar², Nadeem Ahmad'3 ${ }^{3}$ Mumtaz Hussain ${ }^{4}$, Mahendra Singh ${ }^{5}$
}

\section{HOW TO CITE THIS ARTICLE:}

Ahsan Ahmad, Kaushal Kunar, Nadeem Ahmad, Mumtaz Hussain, Mahendra Singh. "Large Nonfunctional Adreno Cortical Carcinoma Masquerading as Renal Cell Carcinoma: A Case Report with Review of Literatures". Journal of Evolution of Medical and Dental Sciences 2014; Vol. 3, Issue 54, October 20; Page: 12492-12495, DOI: $10.14260 /$ jemds/2014/3652

INTRODUCTION: Adrenocortical carcinoma is a rare malignant neoplasm affecting only 1 or 2 person per million population ${ }^{1}$.Nonfunctional malignant tumors particularly present at advanced stage and are associated with poor prognosis. ${ }^{2}$ They are difficult to differentiate from renal cell carcinoma (RCC) especially if they are very large and nonfunctional compressing its native kidney. However, with good preoperative planning in such cases innocuous kidney can be saved.

CASE REPORT: A 50 years old female presented to us with complaints of left upper abdomen lump associated with mild dull ache at same site for four months and irregular fever for three months. She had history of right nephrolithotomy three years back elsewhere. She had no associated comorbidity. Physical examination revealed non-tender, firm mass with lobulated surface occupying whole left hypochondrium. The upper border of mass could not be reached. The hematological and biochemical parameter including renal and liver function test were within normal range.

We had preoperative suspicion of adrenal tumor so we did glucocorticoid, aldosterone, sexual steroid (17 $\mathrm{OH}$ progesterone, testosterone) and urinary metanephrine assay which were within normal range. Computed tomography (CT) of abdomen revealed solid contrast enhancing heterogeneous mass in upper pole of left kidney of about $14 \mathrm{~cm}$ x $12 \mathrm{~cm}$ size. Even CT reporting it as renal mass we added adrenal mass in our differential diagnosis because of large upper polar renal mass. Kidney was approached with $11^{\text {th }}$ rib cutting incision as we had doubt of adrenal gland involvement. The approach also gave us a good exposure of tumor. Intraoperative dissection revealed large suprarenal mass compressing left kidney.

Therefore renal pedicle was carefully separated with sharp and blunt dissection and the adrenal mass was excised after controlling its pedicle. Patient showed good postoperative recovery and did not show any abnormal biochemical profile due to adrenal gland involvement. She is doing well at almost one year of follow up.

We did clinical examination, LFT. Chest X ray and USG at six month and one year which were within the normal range. We have planned for CECT abdomen at two year because tumor was nonfunctional adrenocortical carcinoma. Her histopathological examination of slides showed nuclear atypia, necrosis and more compact cells with low percentage of clear cells in both low and high power magnification. High power magnification also showed diffuse architecture of cells (trabecular pattern). 


\section{CASE REPORT}

DISCUSSION: Adrenocortical carcinoma is a rare adrenal cancer of which $80 \%$ are functional ${ }^{3}$. Functional tumor is common in young females and children whereas nonfunctional tumor occurs more frequently in elderly.

Early diagnosis of adrenal cortical carcinoma is very difficult especially in nonfunctioning carcinoma. ${ }^{4}$ Klausner et al reviewed the literature and found that fever is encountered in $6-10 \%$ of cases with adrenal tumors sometimes as first manifestation of disease. ${ }^{5}$ Flammingo et al reported a case of large nonfunctioning adrenal cortical carcinoma with a $24 \times 18 \mathrm{~cm}$ mass. ${ }^{6}$

The patient had pre-operative fine needle biopsy suggestive of RCC without any clinical sign of adrenal carcinoma. However, per operative the mass seemed to be of adrenal origin and was distinct from kidney which was preserved. Azhar A Khanet al reported a case of giant adrenal cortical carcinoma $30 \mathrm{cmx} 25 \mathrm{~cm}$ mass mimicking as RCC in which radical nephrectomy specimen histopathology revealed diagnosis of adrenocortical carcinoma. ${ }^{2}$

Kuneida et al reported a patient in whom a giant adrenal cortical carcinoma was found to have recurred in the contralateral adrenal gland 6 years after the operation. ${ }^{7}$ They also concluded that large tumor are associated with better prognosis because aggressive tumors give rise to distant metastasis and therefore symptomatic at an early stage.

CT and magnetic resonance imaging can be used for diagnosis and provide useful information about local invasion or spread to kidney with a sensitivity of more than $90 \%$. However, sometimes a large tumor compressing renal parenchyma, the diagnosis can be missed. Tumor size $7-8 \mathrm{~cm}$ has $47 \%$ like hood of malignancy. ${ }^{8}$ Open adrenalectomy with en bloc excision if needed has been the main stay for the treatment of primary and recurrent tumors. Neo adjuvant chemotherapy or adjuvant chemotherapy in such cases is not very effective. ${ }^{9}$

\section{REFERENCES:}

1. Copeland PM. The incidentally discovered adrenal mass. Ann Intern Med1983; 98: 940-47.

2. Khan A A, Iqbal S, Sergill, Rizwan H, Sandeep, S Gujral. Giant nonfunctioning carcinoma of the adrenal cortex mimicking renal cell carcinoma. a diagnostic dilemma. Urology2007; 70: 178. e1-2.

3. Luttom JP, Cerdas S, Billaud L.clinical features of adrenocortical carcinoma, prognostic factors.

4. Nq L, Libertino JM. adrenal cortical carcinoma diagnostic evaluation. J urol 2003; 169: 5-11.

5. Klausner JM, Nakash R, Inbar M, Gutman M, Leleusk S, Rozin R.Prolong fever as a presenting symptoms in adrenal tumors.Oncology1988; 45: 15-7.

6. Flammingo A, Pettinato G. Giant nonfunctioning carcinoma of adrenal cortex. N Eng J Med 2001; 345: 700.

7. Kunieda K, Saji S, recurrence of giant adrenal cortical carcinoma in the contralateral adrenal 6 year after surgery, report of a case.Surg today 2003; 30: 294-97.

8. Sturgeon C, Shen WT, Clarkoff. Risk assessment in 457 adrenal cortical carcinoma. How much the tumor size predict the likelihood of malignancy. J Am Coll surg 2006; 202: 423-30.

9. Kuraba R, Gallagher SF. Current management of adrenal tumor.Oncology2008; 20: 34-46. 


\section{CASE REPORT}

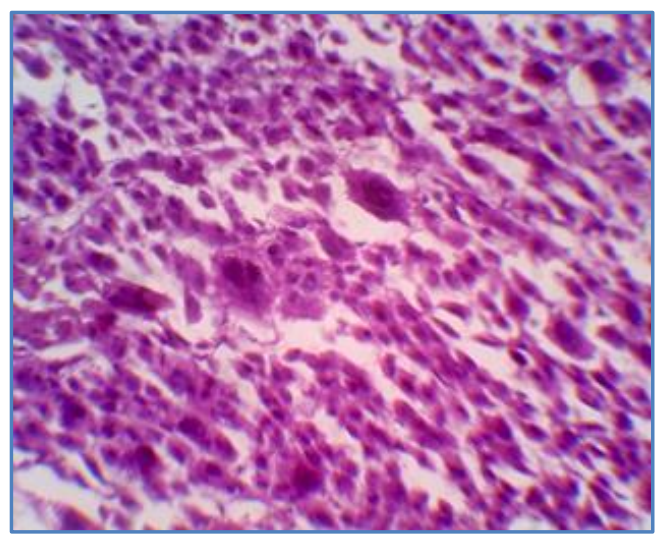

High magnification histopathology showing acc

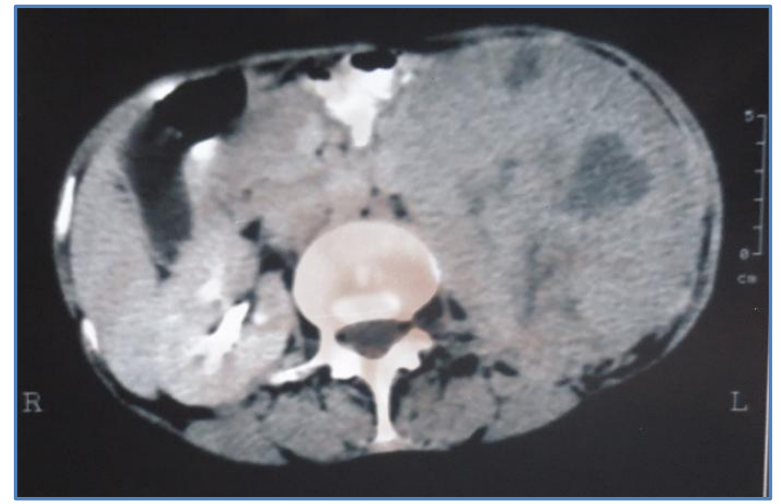

Heterogeneously enhancing left renal area mass

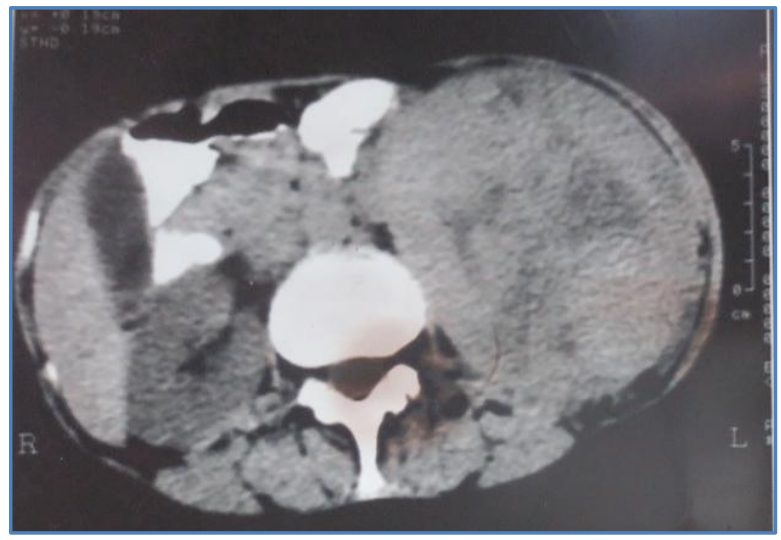

Non-contrast CT scan showing large lump in left renal area 


\section{AUTHORS:}

1. Ahsan Ahmad

2. Kaushal Kunar

3. Nadeem Ahmad

4. Mumtaz Hussain

5. Mahendra Singh

\section{PARTICULARS OF CONTRIBUTORS:}

1. Assistant Professor, Department of Urology, Indira Gandhi Institute of Medical Sciences.

2. Resident, Department of Urology, Indira Gandhi Institute of Medical Sciences.

3. Assistant Professor, Department of Orthodontics, Mithila Dental College, Darbhanga.

4. Assistant Professor, Department of Anesthesiology, Indira Gandhi Institute of Medical Sciences.
5. Professor, Department of Urology, Indira Gandhi Institute of Medical Sciences.

\section{NAME ADDRESS EMAIL ID OF THE CORRESPONDING AUTHOR:}

Dr. Ahsan Ahmad, Assistant Professor, Indira Gandhi Institute of Medical Sciences, Sheikhpura, Patna-800014, India.

Email: ahsanahmad6@gmail.com

Date of Submission: 14/09/2014. Date of Peer Review: 15/09/2014. Date of Acceptance: 14/10/2014. Date of Publishing: 18/10/2014. 